\title{
Novel Approach of Foldscope for Diagnosis of Epithelial Tumors in Animals
}

\author{
Navrose Sangha $^{1 *}$, Charan Kamal Singh ${ }^{1}$, Kuldip Gupta ${ }^{1}$, Vishal Mahajan ${ }^{2}$ \\ and Mandeep Singh Bal ${ }^{2}$
}

${ }^{1}$ Department of Veterinary Pathology, ${ }^{2}$ Animal Disease Research Centre, Guru Angad Dev Veterinary and Animal Sciences University, Ludhiana, Punjab, India

*Corresponding author

\section{Keywords}

Animal, epithelial tumor, foldscope

Article Info

Accepted:

05 June 2020

Available Online:

10 July 2020

\section{A B S T R A C T}

A study was conducted to explore the feasibility of usage of foldscope, for diagnostic accuracy, in comparison to conventional microscopy. The biopsy (95) samples were analyzed by foldscope revealed 21 epithelial tumors that included squamous cell carcinoma $(n=6)$, malignant melanoma $(n=4)$, adenocarcinoma $(n=4)$, mixed mammary tumor $(n=2)$, hepatoid gland adenoma $(n=2)$ and one each of acanthomatous papilloma, basal cell carcinoma and papilloma. It was found that foldscope matched up to $20 \mathrm{X}$ magnification of conventional microscopy. The present study reveals significant promise in the outreach of expert opinion from any laboratory in the world, to any area where interpretation by expert is not available.

\section{Introduction}

Foldscope is a paper based, inexpensive, light weight device that can be carried in a pocket. It gets attached to cell phone with help of magnets. It can provide magnification from $140 \mathrm{X}$ to 2,000X with submicron resolution (Cybulski et al., 2014). Salazar et al., (2016) have used foldscope for screening of cervical cancer.

The present study is therefore, undertaken to explore the feasibility of foldscope for possibility of prompt connectivity of national/inter-national laboratory experts with the routine tissue processing laboratories in the field. This seems to be the first study that compares efficacy of foldscope and conventional microscope, for diagnosis of epithelial tumors in animals.

\section{Materials and Methods}

A total of 95 biopsy samples received in Department of Veterinary Pathology, Guru Angad Dev Veterinary and Animal Sciences 
University, Ludhiana from $1^{\text {st }}$ January 2018 to $31^{\text {st }}$ October 2018 were used in the present study. The biopsy samples submitted in $10 \%$ neutral buffered formalin and processed, blocks were made 4-6 $\mu$ thick paraffin sectioning and stained with Haematoxylin and Eosin technique.

The slides were analyzed using foldscope as well as conventional microscopy and histopathological alterations were compared. Images were taken with cell phone model Galaxy S9, attached with foldscope (identity number 0002A7DB323F).

The images of tumors using foldscope were equivalent to $20 \mathrm{X}$ magnification images of conventional microscope.

\section{Results and Discussion}

The tumors were diagnosed by foldscope in 21 out of 95 biopsy samples. Six biopsy samples were diagnosed as squamous cell carcinoma (Figure1: F1); Four samples each were malignant melanoma (Figure1: F2) and adenocarcinoma (Figure1: F3)

Two each were mixed mammary tumor (Figure 1: F4) and hepatoid gland adenoma (Figure1: F5) and one each were acanthomatous papilloma (Figure1: F6), basal cell carcinoma (Figure1: F7) and papilloma (Figure1: F8).

The slides of epithelial tumors were rescreened using conventional microscopy, wherein, all types of epithelial tumors (Figure2: M1 to M8) were duly confirmed.

There is complete agreement between the diagnosis of tumors using foldscope and conventional microscope. Examination of squamous cell carcinoma revealed hyperplasia of stratum spinosum with presence of keratinous pearls along hyperchromasia and pleomorphism of nuclei as reported earlier (Chandrashekaraiah et al., 2011). Examination of malignant melanoma slides revealed atypical pleomorphic cells with presence of varying amount of melanin pigment as reported earlier by Neelam et al., (2016).

Sections of hepatoid gland adenocarcinoma revealed presence of large cells which had centrally placed nucleus in sheets appearing similar to hepatocytes.

Similarly, Venugopal et al., (2014) reported presence of neoplastic cells with eosinophilic cytoplasm; vacuolation and nuclei were pleomorphic with prominent nucleoli.

Mixed Mammary Tumor examination revealed proliferation of glandular epithelium and mesenchymal cartilaginous growth along with epithelial mesenchymal transition zones. These features were in agreement with the observation of Pawar et al., (2015).

In the case of hepatoid gland adenoma, microscopic changes include proliferative changes with cytological atypia with cells resemble with hepatocytes as similar to Yumusak et al., (2016).

Examination of acanthomatous papilloma revealed marked increased thickness of stratum spinosum layer as reported by Das et al., (2013).

The pelisading appearance, with cells appearing glandular, cuboidal cells along with proliferating nests of basaloid cells was observed in basal cell carcinoma as reported earlier by Kumar et al., (2016).

Papilloma revealed presence of fingerlike projections and cluster of cells surrounded by a basement membrane as reported by Jangir et al., (2017). 


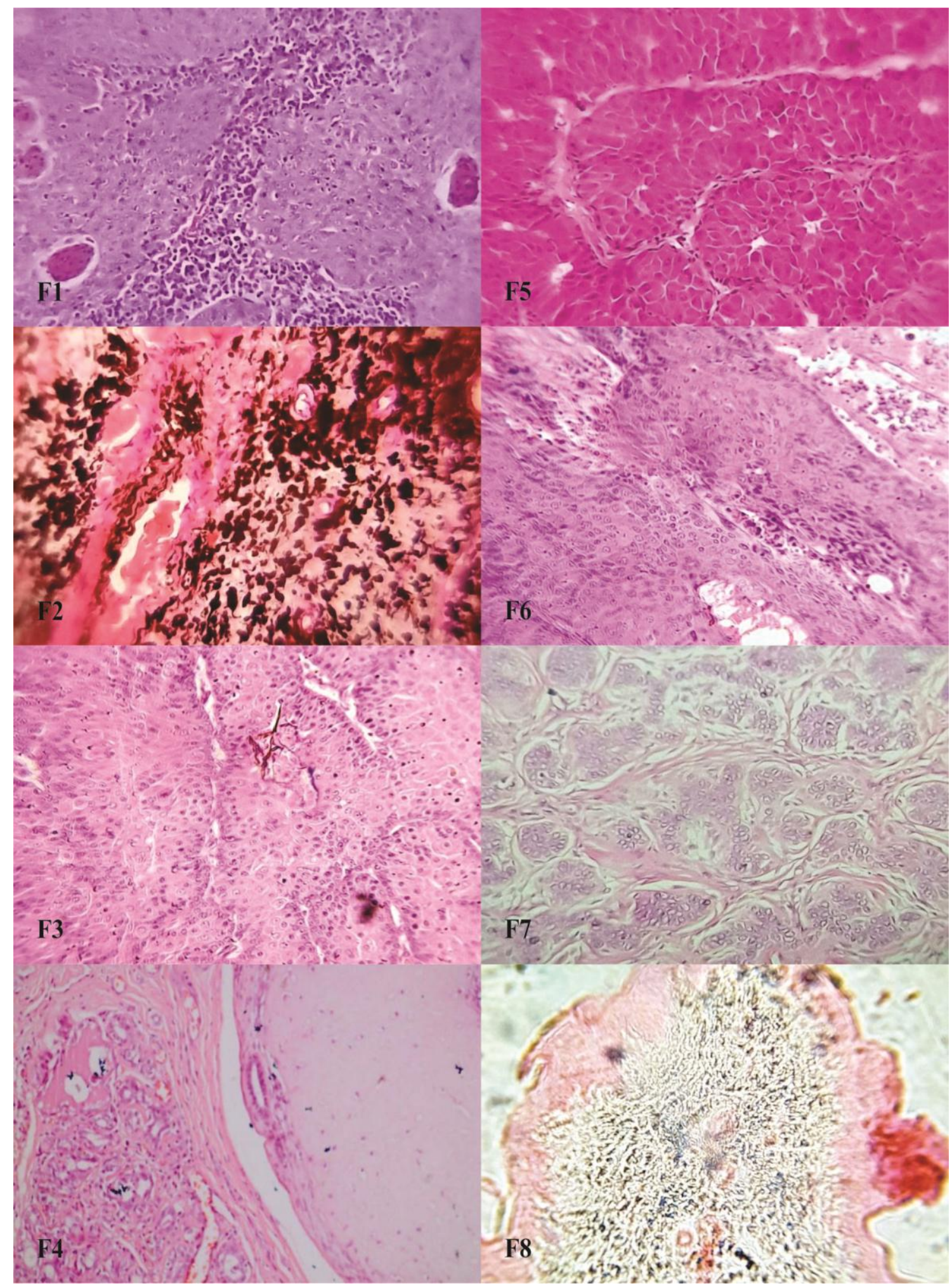

Figure.1 Tumor images by Foldscope

F1 Squamous cell carcinoma, F2 Melanoma, F3 Hepatoid gland carcinoma, F4 Mixed mammary tumor, F5 Hepatoid gland adenoma, F6 Acanthomatous papilloma, F7 Basal cell carcinoma and F8 Papilloma 


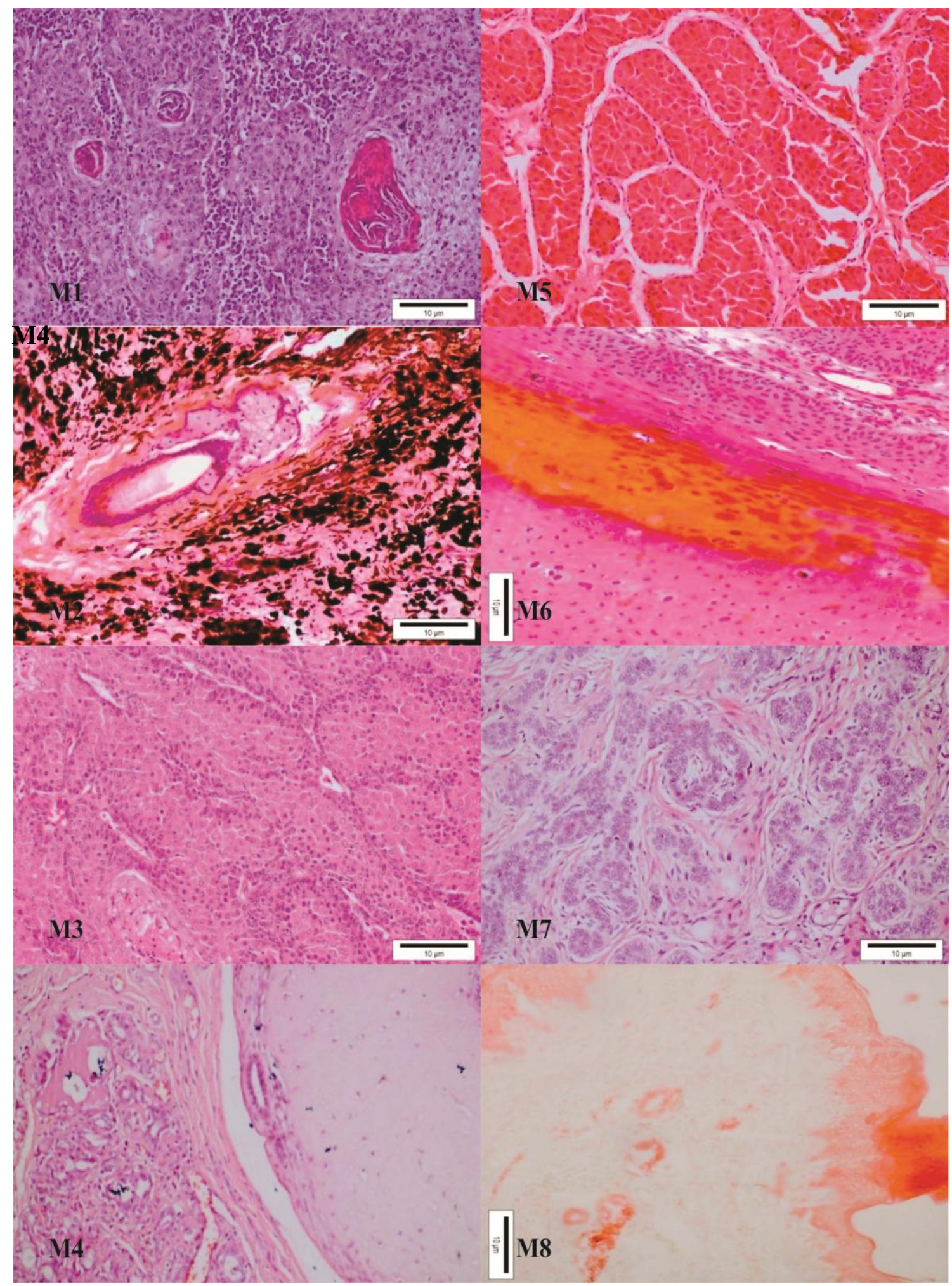

Figure.2 Tumor images by Conventional microscope H\&E X 20x

M1 Squamous cell carcinoma, M2 Melanoma, M3 Hepatoid gland carcinoma, M4 Mixed mammary tumor, M5 Hepatoid gland adenoma, M6 Acanthomatous papilloma, M7 Basal cell carcinoma and M8 Papilloma 
The present study on foldscope, may serve as a reference and offers promise for future linkages of expertise of international laboratories with field conditions especially in developing countries.

\section{Acknowledgement}

The authors are grateful to the Department of Biotechnology [DBT-Prakash Lab Foldscope Project, Category-B (BT/IN/Indo-US/ Foldscope/39/2015 dated $20^{\text {th }}$ March 2018)], Government of India for providing financial support for the current study. The authors are thankful to Directorate of Research and Department of Veterinary Pathology, Guru Angad Dev Veterinary and Animal Sciences University for providing facilities to carry out the work.

\section{References}

Chandrashekaraiah, G.B., Rao, S., Munivenkatappa, B.S. and Mathur, K.Y. 2011. Canine squamous cell carcinoma: a Review of 17 Cases. Brazilian Journal of Veterinary Pathology, 4: 79-86.

Cybulski, J.S., Clements, J. and Prakash, M. 2014. Foldscope: Origami-Based Paper Microscope. Public Library of Science One, 9: e98781.

Das, S., Nath, B.K., Alim, M.A., Sikder, S. and Pollob, M.S. 2013. Acanthomatous ameloblastoma in a female Spitz dog with rare atypical histomorphology: A case Study. Veterinary World, 6: 219-222.

Jangir, B.L., Bind, R.B., Kumar, P. and Somvanshi, R. 2017. Pathological studies and detection of different bovine papilloma virus types in buffalo cutaneous warts. Turkish Journal of Veterinary and Animal Sciences, 41: 306-311.

Kumar, A., Chauhan, A. and Kashyap, S. 2016. Basal cell carcinoma in oculo-cutaneous albinism. International Journal of Research in Medical Sciences, 4: 24522454.

Neelam, S.K., Nandyala, V.N.R., Shyamala, S., Pallam, P., Chintakindi, S.B. and Odapally, S.K. 2016. Pigmented epitheloid melanocytoma: a low grade/ intermediate/ borderline melanoma. International Surgery Journal, 3: 400-403.

Pawar, Y., Kadam, D., Khandekar, G. and Nehte, R. 2015. Gross and Cytological evaluation of canine spontaneous mammary neoplasms and its correlation with histopathology and morphometric analysis. International Journal of Veterinary Science, 4: 104-110.

Salazar, J.M., Bruno, M., Zumaran, V.R., Bhamla, S. and Prakash, M. 2016. Implementation of the Foldscope as a device for cervical cancer diagnosis: Averification and evasluation study. Revista latinoamericana de patologia clinica medicina laboratorio, 63: 141-147.

Venugopal, S.K., Anoop, S., Sarangom, S.B., Krishna, B.D. and Nithina, K.B. 2014. Hepatoid Gland Adenocarcinoma in a Dog. Indian Veterinary Journal, 91: 62 - 63.

Yumusak, N., Çalişkan, M. and Kutsal, O. 2016. Fine needle aspiration cytology (FNAC) in the diagnosis of canine hepatoid gland tumors- A comparative study with histopathology. Ankara Universitesi Veteriner Fakultesi Dergisi, 63: 259-266.

\section{How to cite this article:}

Navrose Sangha, Charan Kamal Singh, Kuldip Gupta, Vishal Mahajan and Mandeep Singh Bal. 2020. Novel Approach of Foldscope for Diagnosis of Epithelial Tumors in Animals. Int.J.Curr.Microbiol.App.Sci. 9(07): 156-160. doi: https://doi.org/10.20546/ijcmas.2020.907.019 